\title{
Pragmasynergetic potential of educational- pedagogical discourse as a new form of reflection
}

\author{
Elena Sakharova ${ }^{*}, 1$ and Nadezhda Revyakina ${ }^{1}$ \\ ${ }^{1}$ Don State Technical University, 344003, Gagarin sq., 1, Rostov on Don, Russia
}

\begin{abstract}
In this article, methodological principles and discourse are investigated within the framework of an interdisciplinary pragmasynergetic approach. We are talking about the process of self-organization of educational-pedagogical discourse, the formation of its structure and shaping of the electronic courses as means of optimizing the educational process in order to create conditions for quality teaching. This approach is also important because at present there is the problem of preserving the quality of knowledge while implementing intensive electronic methods of mastering foreign language communication skills. In response to the needs of modern society, a new scientific paradigm is being formed. In particular, in linguistics and linguodidactics, the direction is developing that studies the problems of language, text, discourse combining it with the ideas of synergetics - the theory of self-organization of complex systems. The postulates of pragmalinguistics largely correspond to synergetic principles and indicate the need to integrate these sciences. The significance of the article lies in the fact that the pragmasynergetic interpretation of educational-pedagogical discourse contributes to the development of the study of the structure of discourse as an integral dynamic system.
\end{abstract}

\section{Introduction}

In the 21st century, global social changes have taken place and continue to develop, which in one way or another are associated with the evolution of the electronic environment. They have a significant impact both on the life of society as a whole and on the consciousness of individuals. Rapid growth of information and communication technologies contributes to the active virtual-spatial development of the real world. Information of a wide variety of content appears which is accumulated, multiplied, and broadcasted in incredible quantities.

The relevance of the study is due to the need for a systematic analysis of the process of self-organization of educational-pedagogical discourse as a complex dynamic system of speech-thinking activity of subjects interacting through educational texts. Theoretical comprehension requires the use of educational texts as the main way of developing communication skills and abilities.

\footnotetext{
* Corresponding author: elenasakharova@bk.ru
} 
Achievements of the exact sciences and their advanced methods become available to specialists in other areas of scientific knowledge. The rethinking of the goals and results of already conducted and only planned studies takes place. All this leads to the fact that there is a change in the research paradigm in science. To achieve greater success, science makes the transition to an interdisciplinary field, towards convergent knowledge [1-3].

Convergent knowledge is built on the ideas of cooperation and development according to the principle of complementarity, the interdependence of nature and society, the development of creativity and innovation, and a holistic system approach, when specialists from various fields are involved in a scientific dialogue [4]. With the convergence of several subject areas, a complex and deeper description of a variety of phenomena of the surrounding world, including social ones, is obtained.

The direction that ensures the integrity of the transmission and perception of information is a synergetic approach, actively developed recently by outstanding scholars [5-9].

The foundations of synergetics were laid by I.R. Prigozhin, professor at the Free University of Brussels. He presented it as the science of self-organization, or the science of the complexity. The very term "synergetics", which in translation from Greek means "to act together", was introduced into scientific circulation by Hermann Haken, professor at the University of Stuttgart. The scientist defined synergetics as the science of joined substructures actions in a nonlinear open system [10-11]. In his opinion, synergetics can explain the multidimensionality of the existing world. The researcher considers any object, phenomenon, process as a complex nonlinear system that functions and develops with the coordinated interaction of all subsystems (parameters) included in it. Here, the research focuses on various aspects of the system's self-organization. The possibilities for selforganization are caused by chaotic movements within the system itself (fluctuations), while individual parameters can undergo rapid jump-like changes, leading to chaos within the system (bifurcation), as a result of which the system itself evolves (self-organization), i.e. gets a new quality, is supplemented with new elements, follows a new path of its development.

The presence of such a research object as an open nonlinear dynamic system allows the usage of synergetics in various fields of both natural science and humanitarian cycles. It is relevant to use the ideas of synergetics where there are complex systems that can evolve. In this case, synergetics acts as an interdisciplinary language and methodology of modern science.

The purpose of this article is to substantiate the application of synergetic analysis to the features of educational-pedagogical discourse and its narrative characteristics. We believe it is relevant to apply an integrated pragmasynergetic approach to the process of teaching a foreign language, which has turned into a distance format in the current pandemic.

\section{Method}

The synergetic approach is successfully used in the educational-pedagogical sphere [12$16]$.

The system-forming features of educational discourse are rather complicated. They represent communication within the framework of status-role relations. The goal of educational discourse has a three-component nature:

1) in the professional field - the formation of key competencies of the participants in the educational process,

2) in the public life - full socialization of the individual in society,

3 ) in the personal sphere - the formation of a self-valuable personality. 
The main goal of educational discourse is to create conditions for the integrated personal development in the diversity of his psychophysical, social and personal characteristics. The effectiveness of educational discourse can be an important indicator of its humanitarian quality.

Educational-pedagogical discourse, which has informational, semiotic, anthropological and cultural origins, is viewed not only as a product, but as the process of its creation. The results of this process are determined by a number of external and internal factors. External factors are determined by the social and educational environment in which educational discourse is created and functions. Internal factors are connected with the personal qualities of the subjects of the educational process. Thus, the factors in the design of educational discourse are:

a) the reflexive developmental mechanisms of the personality;

b) the developmental activity itself;

c) the social and educational environment.

They form the educational discourse itself in an educational institution (college, university). The values of educational discourse are represented in the consolidation of social traditions. The participants in the educational discourse are the teacher and the student, acting in various communication situations. The positive result of pedagogical interaction is largely determined, according to scientists, by the communicative potential of the teacher's personality and his communication skills.

The strategies of educational discourse are determined by the main goal - human socialization - and are reduced to communicative intentions. The communicative strategy of a teacher-student interaction is determined by the teacher who controls the process of cognitive activity, regulates the relationship between students, creating an atmosphere of friendly and active speech communication. This is a pronounced strategy of partnership and cooperation.

In the educational process, the basic concepts of synergetics - self-organization and management - are interpreted as self-education and self-government. Within this approach, great importance is attached not only and not so much to the subject content of the discipline. It is becoming more and more relevant to teach students various ways of selforganization, self-education, self-upbringing, in particular, methods of self-acquisition of knowledge: finding the necessary information, the ability to process, analyze and interpret it. The process of self-organization leads a person to self-reflection, to a dialogue with himself and, as a result, to the analysis of his abilities, intentions and capabilities. Thus, in a non-linear situation, the inner choice of the individual, the choice of value attitudes, is carried out, and the perception of the situation itself becomes qualitatively different, deeper and more versatile. It contributes to the manifestation of students' creativity.

From the point of view of a synergistic approach, the teacher's function is to observe the students' reasoning and switch the learning process from one level to the next. In this regard, incentives for learning are created to a greater extent not only by the teacher, but also by the team actions and energy of the group.

As for the process of teaching foreign languages, from the point of view of synergetics, it is viewed as a process of managing students' self-learning. The process of teaching a foreign language is an integral systemic education, and the student is a self-governing, selforganizing and self-learning system.

The main task of a foreign languages teacher is to help students in self-organization, development of basic strategies for self-education, formation of algorithms for extracurricular work to master new knowledge. The choice of strategies for personal growth in the study of a foreign language is determined by individual psychological characteristics, cognitive needs, commitment, initiative of students. 
Synergetic ideas are rapidly penetrating into linguistics. If at first it happened mechanically, today scientists are optimistic about the prospects for a synergistic approach in a linguistic description. Synergetic linguistics is just developing, and its conceptual apparatus has not yet been fully organized, but the fact is already obvious that a new type of scientific thinking - synergetic - has been formed. This type of thinking is multiparadigmatic in nature [6] and combines anthropocentric, cognitive and postanthropocentric research paradigms.

The theoretical prerequisite for the application of synergetic principles to the description of linguistic structures is the assertion that language is a complex open self-organizing system, which has such characteristics as nonlinearity, openness, and the ability to develop.

In recent decades, pragmatic concepts dominate in linguistics; they determine the vectors of studying various aspects of language and speech. Scientists raise a variety of issues: they study code problems from the point of view of pragmatics and semantics [15], investigate the pragmalinguistic characteristics of various types of discourse on the speech behavior of message senders [16], and consider the pragmatic features of the context [17]. We believe that pragmalinguistics is the most promising area of synergetic ideas application. Synergetics in this case can act as a modifier and specifier of pragmalinguistic ideas about language, speech, discourse, text and narrative.

\section{Results and discussion}

Pragmasynergetic study of educational-pedagogical discourse within the framework of an integrated approach unites pragmalinguistic categories and research objects with the methodology of synergetics.

An outlook at the objects, phenomena, processes of the surrounding world through the prism of synergetics allows us to consider discourse as a super-complex open selforganizing system [18-20]. Educational-pedagogical discourse includes a set of subsystems, or parameters, closely interacting with each other, on which the qualitative functioning of the entire system (discourse) as a whole depends. These parameters include, first of all, the subjects of communication. In our case - the teacher and students with their intentions, presuppositions, individual characteristics; the purpose within which the subjects act; place and time of the educational process; didactic materials; technical means; various tools (educational programs, timetable, etc.). Moreover, each of the parameters can be considered as a separate open nonlinear system with its own structure and connections with other systems. Therefore, all parameters of the system are subject to constant influence and transformation from the outside, which in turn leads to chaotic movements in the system. In order to continue functioning within the framework of its purpose, its goal, the system starts the mechanisms of self-organization. In other words, it brings the state of chaos to the state of order, and thus evolves.

A clear example of this development of educational-pedagogical discourse is the current situation with the COVID-19 epidemic, when, due to certain restrictions, it suddenly became impossible to conduct classes in the traditional academic environment-in University buildings, classrooms with all their attributes. In the system of educationalpedagogical discourse, the parameter "place" has undergone a significant transformation. The educational process, adapting and self-organizing in the new conditions, has moved to a distance format with the use of information technologies. In this regard, the pragmatics of communication has also changed: the interaction of teachers and students has become mediated, i.e. it was carried out using the Internet and technical devices. All the changes that occurred in the subsystems taking into account the purpose required their reconfiguration, establishing interaction between them and self-organization of the entire 
system. This is how educational-pedagogical discourse develops and evolves in new conditions.

In order to organize the educational process in a distance format at the Don State Technical University on the information and educational portal of the University, teachers created electronic courses (e-courses) within the disciplines framework.

The "landscape" of e-courses for providing distance education is rather heterogeneous, since the teachers who create these courses are targeted to the groups of students of various directions and training profiles. However, we consider it possible to highlight the following features inherent in the created courses (Fig. 1):

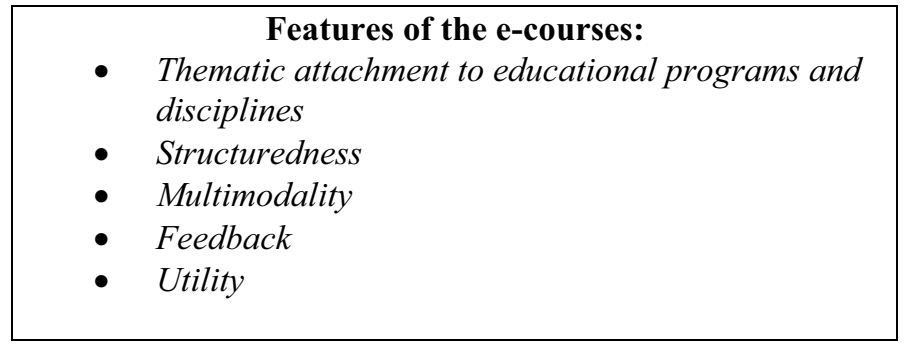

Fig. 1. Features of the e-courses

Thematic attachment to educational programs and disciplines. This feature can be traced both in the names of the courses and in the thematic content that fills these courses.

Structuredness. Electronic courses are clearly structured: they consist of sections that include annotation, recommendations for working with the course, thematic selection of texts, grammar material, exercises and assignments for practicing vocabulary and grammar, test assignments, etc. The necessity, tasks and number of sections are determined directly by the teacher who creates the course.

Multimodality. The material of the courses is offered, as a rule, in various modes: text documents for reading, analysis and translation, audio files for listening, videos, presentations, links to educational materials on other sites and platforms. All this makes it possible to diversify the material and forms of activity in the classroom, makes the classes more interesting and productive, and develops students' independence and creativity.

Feedback. In the structure of the course, a section is allocated for students to complete tests and various creative tasks with the option of commenting (remarks) and giving marks for the work.

Utility. The educational material presented in electronic courses in a foreign language contains professionally oriented information, as well as algorithms for working with special texts. This promotes the development of universal and professional skills, which will be useful in practical activities.

Sure, e-courses in the discipline can not, and should not replace an off-line educational process and communication between the teacher and students. However, in the current situation of a viral epidemic, when it is impossible to conduct classes in traditional conditions, such a new component in the system of educational-pedagogical discourse are quite appropriate.

The course is a kind of conductor between the subjects of communication and performs a number of important functions:

Organizational - allows the teacher to keep in touch with students in the auditorium and outside it;

Pragmatic - allows to manage the teaching process, build differentiated interaction with students; 
Educational-practical - contains the necessary material for the practical mastering of a foreign language both for working in a group online and for self-training of students;

Controlling - allows the teacher to control the knowledge of students.

Thus, e-courses on the discipline within the framework of educational-pedagogical discourse are the result of self-organization of the system, its evolution. They are included in the educational process as a new system parameter that determines the smooth and effective functioning of the entire system in online learning.

Analysis of the textual empiricism of the created courses for teaching students a foreign language at the World Languages and Cultures Chair allows us to conclude that materials (texts in print, as well as in audio and video formats) of informational, artistic, journalistic, and analytical nature have narrative character. The narrative nature of information in educational-pedagogical discourse is determined by the specifics of the educational sphere and subject content. This determines, in particular, the selection of the material necessary for foreign language classes. First of all, we note denotative information from professional spheres in a foreign language, which is accompanied by various kinds of tasks that encourage students to reason about the topic covered, which is a typical narrative feature.

Let us consider the features of the narrative structure in distance learning foreign language courses for DSTU students. A large amount of information allows to identify the following markers of narrative in them: nonlinear development of the space-time continuum and the communicative plan of presentation of educational means.

In the e-course "Foreign Language for Students of Media Communications and Modern Technologies", the focus is on the denotational aspect of narration, as well as on elements of the evaluative tonality. In the electronic resource, course authors often use denotative elements of the news continuum, typical for mass media.

The course "Foreign Language for Students of the Department of Physical Education and Sports" is designed in such a way that students of this department could feel the inextricable connection of the material presented in the course for distance learning with realities of life. Pre-text assignments, the text and post-text exercises contribute not only to increasing the general outlook of students, but also to the development of their professional and general cultural competence. The course is also built on the basis of complementarity, nonlinearity, openness, flexibility and has a high degree of utility.

The e-course "Foreign Language for Students of the Service and Hotel Business" within the framework of distance learning also has narrative-forming features of complementarity, nonlinearity, transparency, flexibility. The material is presented in such a way that students can gain knowledge that will be useful for them in their future profession.

In the educational process, synergistic pedagogical technologies are the guarantors of ensuring multivariance. Synergistic learning provides each student with the opportunity for independent and extraordinary movement towards success by creating conditions for choice and alternatives. The student begins to understand himself, his capabilities, interests, strengths and weaknesses, talents and life priorities. In addition, through synergistic learning, learners begin to understand others and accept them. This feature of synergetics allows teachers to more effectively organize the learning process and clearly present the results of this process.

\section{Conclusions}

Analysis of the features of educational-pedagogical discourse in modern conditions lets us draw the following conclusions:

Pragmasynergetic approach to the study of discourse is advisable to be used not only in linguistics but in the educational process as well. This approach helps to understand the features of the structure and functioning of the discourse. 
Educational-pedagogical discourse in the aspect of pragmasynergetics is an open nonlinear dynamic system within the educational process. The efficiency of the system depends on the clear interaction of all parameters.

Electronic courses created by teachers for distance learning are in an inclusive relation to educational-pedagogical discourse, being its structural parameter. They are built into the educational process and perform a number of important functions: organizational, educational-practical, pragmatic, controlling.

Electronic courses in foreign languages within the framework of educationalpedagogical discourse have the following characteristics: thematic attachment to educational programs and disciplines, structuredness, multimodality, feedback, utility.

The material of e-courses is narrative in nature, which manifests itself in complementarity, transparency, flexibility.

\section{References}

1. M. C. Roco, et al., Innovative and Responsible Governance of Converging Technologies. Convergence of Knowledge, Technology and Society. Science Policy Reports. Springer, Cham (2013) https://doi.org/10.1007/978-3-319-02204-8_10

2. M. Williams, W. Steffen, P. Crutzen, The New World of the Anthropocene. Environmental science \& technology, 44(7), 2228-2231 (2010)

3. M. Lundstrom, H. S. Philip Wong, Convergence Platforms: Foundational Science and Technology Tools. Convergence of Knowledge, Technology and Society. Science Policy Reports. Springer, Cham (2013) https://doi.org/10.1007/978-3-319-02204-8_1

4. O. E. Baksansky, Philosophy and Culture, 7(79), 1061-1068 (2014) DOI: https://doi.org/10.7256/1999-2793.2014.7.11995

5. S. C. Müller, P. J. Plath, G. Radons, A. Fuchs (Hrsg.), Complexity and Synergetics (2018) DOI: 10.1007/978-3-319-64334-2

6. V. G. Budanov, I. A. Aseeva, Anthropology archaeology history and philosophy medieval \& renaissance studies, 2, 565-573 (2017) DOI: https://doi.org/10.5593/sgemsocial2017/22/S09.075

7. G. Buenstorf, Evolution, Organization and Economic Behaviour. Edward Elgar Publishing, 253 (2012)

8. R. Fusaroliab, J. Rączaszek-Leonardic, K. Tylénab, New Ideas in Psychology, 32, 147-157 (2014) https://doi.org/10.1016/j.newideapsych

9. W. Tschacher, M. Tröndle, Futures, 43(1), 67-75 (2011) https://doi.org/10.1016/j.futures.2010.06.001

10. H. Haken, J. Portugali, Royal Society Open Science, 6, 8 (2019) DOI: 10.1098/rsos. 191087

11. H. Haken, Synergetics: Is self-organization governed by universal principles? In: The Evolutionary Vision: Toward A Unifying Paradigm of Physical, Biological and Sociocultural Evolution, 15-24 (2019)

12. M. Petrenko, Procedia - Social and Behavioral Sciences, 214, 407-413 (2015) https://doi.org/10.1016/j.sbspro.2015.11.690

13. S. I. Osipova, V. S. Okuneva, Modern problems of science and education, 3 (2012) URL: https://www.science-education.ru/en/article/view?id=6213 
14. L. I. Tararina, E. E. Sokolova, E. V. Limarova, L. N. Ivanova, S. N. Fedorova, A. G. Oshaev, S. A. Chernov, E. R. Khairullina, Mediterranean Journal of Social Sciences, 6(2), 98-104 (2015). DOI:10.5901/MJSS.2015.V6N2S3P98

15. T. Belligh, K. Willems, Language Sciences, 83, (2021) https://doi.org/10.1016/j.langsci.2020.101310

16. N. P. Revyakina, E. E. Sakharova, Russian Linguistic Bulletin, 2(22), 38-40 (2020) http://rulb.org/wp-content/uploads/wpem/pdf_compilations/2(22)/2(22).pdf accessed 13.06.2020)

17. J. Kolkmann, I. L. Falkumb, Journal of Pragmatics, 157, 1-16 (2020) https://doi.org/10.1016/j.pragma.2019.10.004

18. S. K. Gural, Procedia - Social and Behavioral Sciences, 154, 3-7 (2014) https://doi.org/10.1016/j.sbspro.2014.10.103

19. T. Dombrovan, An Introduction to Linguistic Synergetics. Cambridge Scholars Publishing (2018)

20. Y. A. Nyman, S. K. Gural, V. M. Smokotin, M. A. Bovtenko, Language and Culture, 21 90-106 (2013) 